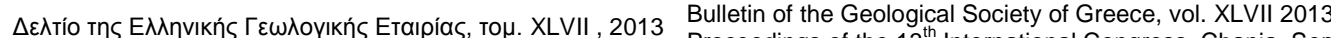
Proceedings of the $13^{\text {th }}$ International Congress, Chania, Sept.

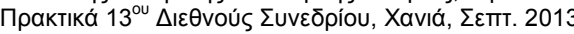
2013

\title{
ROCK MASS BLASTABILITY DEPENDENCE ON ROCK MASS QUALITY
}

\author{
Chatziangelou M. ${ }^{1}$ and Christaras B. ${ }^{2}$ \\ ${ }^{I}$ Department of Civil Infrastructure Engineering, School of Technological Applications of \\ Thessaloniki, Greece, mcha@geo.auth.gr \\ ${ }^{2}$ Department of Geology, Aristotle University of Thessaloniki, Greece, christar@geo.auth.gr, \\ tel./fax. +3023198506, mobile: +306944332554
}

\begin{abstract}
The present paper tries to investigate the influence of rock mass quality characteristics on blasting results. In order to come to some conclusions, blastability and quality of rock mass were put together using the already known classification systems. Taking into account the quantity of blastability index (BI) for every possible structural appearance of the poor rock mass, the relation of discontinuities characteristics and blastability index are investigated. The estimations of the above trial gave arise on a new classification system being called "Blastability Quality System (BQS)", which can be an easily and wide use tool as it is a quickly calculator for blastability index (BI) and rock mass quality.

Key words: Blastability, rock mass, quality, classification.
\end{abstract}

\section{Пєрі́ $\eta \psi \eta$}

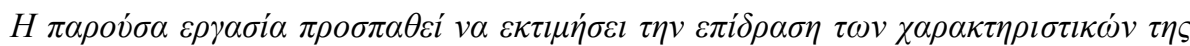

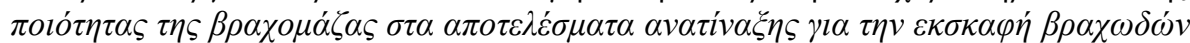

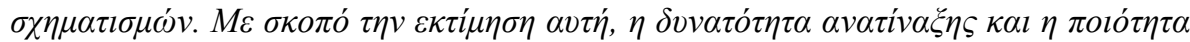

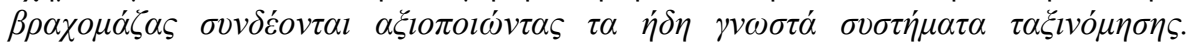

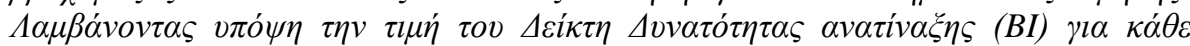

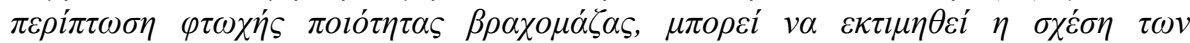

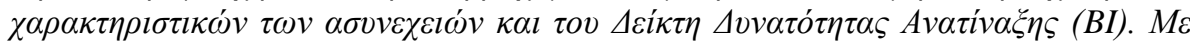

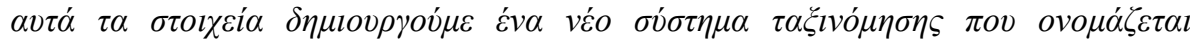

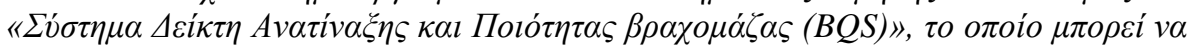

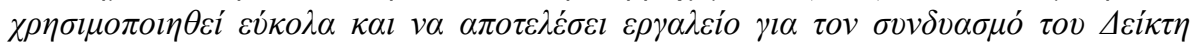

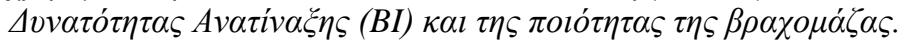

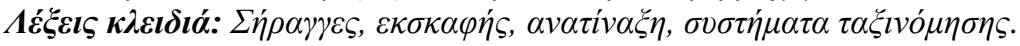

\section{Introduction}

Many rock mass quality classification systems -RQD (Deere, 1989), Q (Barton et al, 1980), RMR (Bieniawski, 1989), GSI - have been developed for drilling and excavation ability estimation, but not for blasting calculations (Jimeno et al, 1995). The several rock types of rock mass, which are affected by numerous stages of alteration in varying stress conditions, may be explored in a

XLVII, No 3 - 1694 
different manner under specified blast design, explosive characteristics and specified legislative constraints depending on structural characteristics.

The present paper investigates the influence of rock mass quality characteristics on blasting results. Rock blastability (Kaushik \& Phalguni, 2003, Murthy et al, 2003) is quantified using the blastability index, which is calculated based on geotechnical characteristics. Rock mass quality can also be estimated using the already known classification systems. The relation between discontinuity characteristics and blastability index for every possible structural appearance of the poor rock mass is estimated. The above estimations can be used in a new classification system called "Blastability Quality System (BQS)".

The rock mass in this study is poor and friable, shared with lack of blockiness due to close spacing of weak schistosity or sheer planes and disintegrated with poorly interlocked, heavily broken rock mass with mixture of angular and rounded rock pieces (Hoek et al, 1998). Although the quality is very poor, a light blast may be needed as the small rock pieces are tightly connected.

\section{Connecting Blast Ability and Quality Ability}

The laminated and sheared rock mass, with lack of blockiness due to the close spacing of weak schistosity or sheer planes and disintegrated rock mass, with poorly interlocked, heavily broken rock with mixture of angular and rounded rock pieces, which are described by the lower part of the GSI diagram (Hoek, 1983, Hoek \& Brown, 1997, Marinos and Hoek, 2000), is divided into eight parts (Fig.1); A - GSI about $0-12, \mathrm{~B}-$ GSI about 12-23, C GSI about 22-23, D - GSI 7-17, E GSI about 18-28, F - GSI about 16-36, G - GSI 35-43, H - GSI 42-50.

Taking into account the parameters of the Blastability Index (Scott, 1996) (BI $=0.5 \mathrm{x} \quad(\mathrm{RMD}+\mathrm{JPS}+\mathrm{JPO}+\mathrm{SGI}+\mathrm{H})$ (Lilly, 1986), the Blastability Index (BI) is calculated for every possible combination of the above parameters, which refers to powdery/friable rock mass. That means RMD (rock mass description) is equal to 10 (powdery / friable rock mass). JPS (joint plan spacing) is used equal to 10 for closely spacing, 20 for intermediate spacing and 50 for widely spacing. JPO (joint plane orientation) is used equal to 10 for horizontal discontinuities, 20 for

Table 1 - Specific gravity influence (SGI).

\begin{tabular}{|c|c|}
\hline SGI & $\begin{array}{l}\text { specific gravity of } \\
\text { rock }\left(t / \mathbf{m}^{3}\right)\end{array}$ \\
\hline $\begin{array}{l}25 * \text { specific gravity of } \\
\quad \operatorname{rock}\left(t / \mathrm{m}^{3}\right)-50\end{array}$ & \\
\hline$-22,5$ & 1,1 \\
\hline-20 & 1,2 \\
\hline$-17,5$ & 1,3 \\
\hline-15 & 1,4 \\
\hline$-12,5$ & 1,5 \\
\hline-10 & 1,6 \\
\hline$-7,5$ & 1,7 \\
\hline-5 & 1,8 \\
\hline$-2,5$ & 1,9 \\
\hline 0 & 2 \\
\hline 2,5 & 2,1 \\
\hline 5 & 2,2 \\
\hline 7,5 & 2,3 \\
\hline 10 & 2,4 \\
\hline 12,5 & 2,5 \\
\hline 15 & 2,6 \\
\hline 17,5 & 2,7 \\
\hline 20 & 2,8 \\
\hline 22,5 & 2,9 \\
\hline 25 & 3 \\
\hline
\end{tabular}
inclined discontinuities where the excavation drives against dip direction, 30 for inclined discontinuities with strike parallel to face, 40 for declined discontinuities where the excavation drives with dip direction. SGI (specific gravity influence) is calculated using specific gravity of rocks $\left(\mathrm{t} / \mathrm{m}^{3}\right)$ (table 1). 2400 different rock mass combinations are estimated (tables 2, 3, 4). 


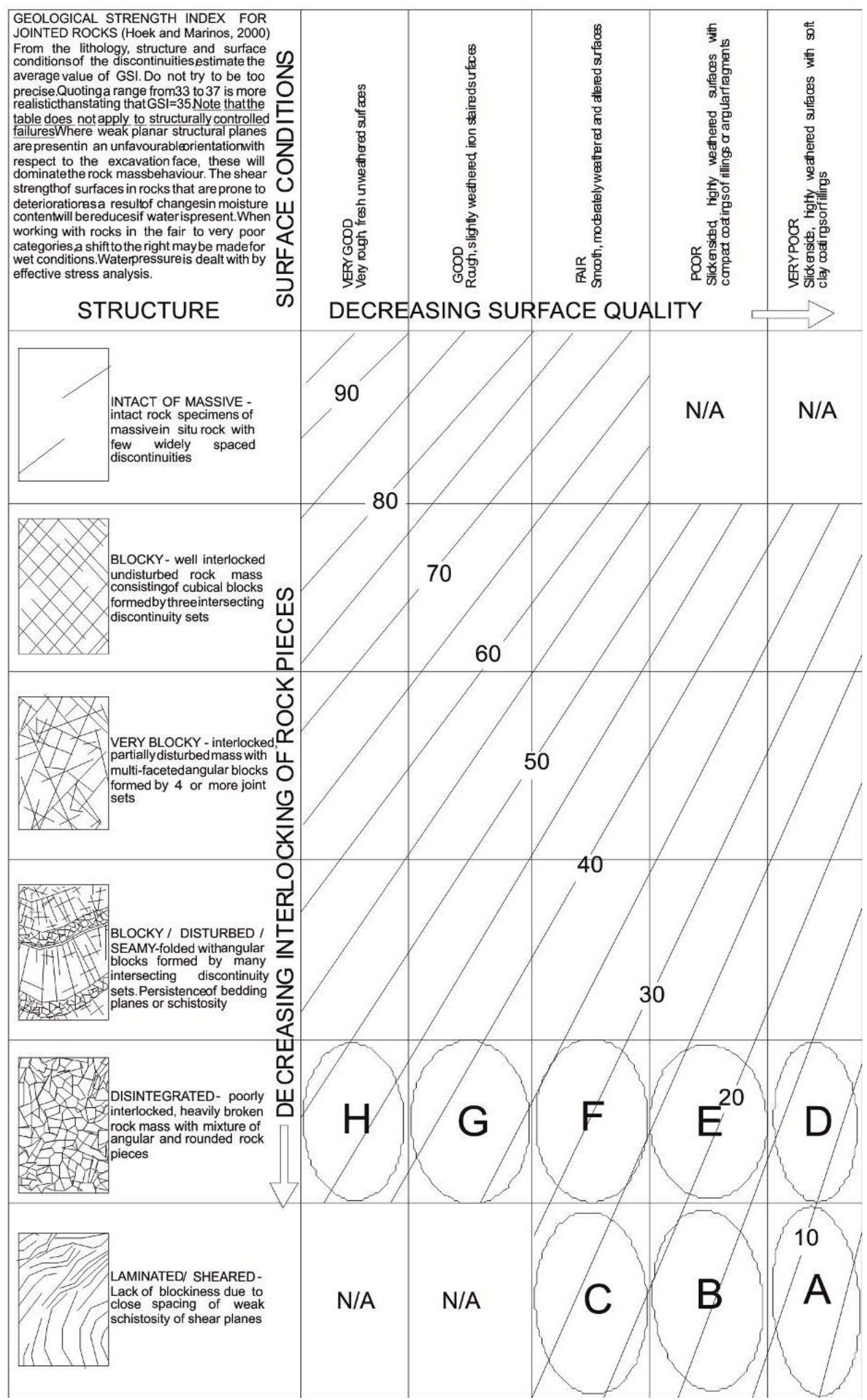

Figure 1 - Eight part division of GSI diagram.

$\underline{\text { XLVII, No } 3-1696}$ 
The blastability index, of a rock mass with closely spaced discontinuities is calculated as shown in table 2. The blastability index, of a rock mass with intermediate spaced discontinuities, is calculated in table 3 . The blastability index, of a rock mass with widely spaced discontinuities, is calculated in table 4. The parameters of BI calculation are also presented in the above tables, where the different rock mass types are numbered from 1 to 2400 .

Subsequently, the above rock structures are grouped according to RMR range and GSI parts, taking into account rock mass hardness a well as discontinuities' spacing and orientation. Additionally, the calculation of the range of BI is presented in tables 5, 6, 7, 8, 9, 10, 11, 12. GSI range is calculated, in tables 5,6,7,8, for every rock mass type with a specific RMR. The different types of rock mass are also numbered from 1 to 2400 and they are grouped together according to RMR range. In the same tables, GSI parts are equivalent to RMR range. Actually, 90000 rock mass types are investigated. In tables $9,10,11,12$ the blastability index is appeared for the above grouped rock masses in addition to the GSI parts. In the same tables the RMR range is equivalent to the GSI parts.

Table 2 - BI calculations for closely spacing discontinuities.

\begin{tabular}{|c|c|c|c|c|c|c|c|c|c|c|c|c|c|}
\hline $\mathbf{A} / \mathbf{A}$ & RMD & JPS & JPO & SGI & H & BI & $\mathbf{A} / \mathbf{A}$ & RMD & JPS & JPO & SGI & H & BI \\
\hline $001-20$ & 10 & 10 & 10 & from $-22,5$ to 25 & 1 & $4,25-28$ & $401-420$ & 10 & 10 & 30 & from $-22,5$ to 25 & 1 & $14,25-38$ \\
\hline 2140 & 10 & 10 & 10 & from $-22,5$ to 25 & 2 & $4,75-28,5$ & $421-440$ & 10 & 10 & 30 & from $-22,5$ to 25 & 2 & $14,75-38,5$ \\
\hline $41-60$ & 10 & 10 & 10 & from $-22,5$ to 25 & 3 & $5,25-29$ & $441-460$ & 10 & 10 & 30 & from $-22,5$ to 25 & 3 & $15,25-39$ \\
\hline $61-80$ & 10 & 10 & 10 & from $-22,5$ to 25 & 4 & $5,75-29,5$ & $461-480$ & 10 & 10 & 30 & from $-22,5$ to 25 & 4 & $15,75-39,5$ \\
\hline $81-100$ & 10 & 10 & 10 & from $-22,5$ to 25 & 5 & $6,25-30$ & $481-500$ & 10 & 10 & 30 & from $-22,5$ to 25 & 5 & $16,25-40$ \\
\hline $101-120$ & 10 & 10 & 10 & from $-22,5$ to 25 & 6 & $6,75-30,5$ & $501-520$ & 10 & 10 & 30 & from $-22,5$ to 25 & 6 & $16,75-40,5$ \\
\hline $121-140$ & 10 & 10 & 10 & from $-22,5$ to 25 & 7 & $7,25-31$ & $521-540$ & 10 & 10 & 30 & from $-22,5$ to 25 & 7 & $17,25-41$ \\
\hline $141-160$ & 10 & 10 & 10 & from $-22,5$ to 25 & 8 & $7,75-31,5$ & $541-560$ & 10 & 10 & 30 & from $-22,5$ to 25 & 8 & $17,75-41,5$ \\
\hline $161-180$ & 10 & 10 & 10 & from $-22,5$ to 25 & 9 & $8,25-32$ & $561-580$ & 10 & 10 & 30 & from $-22,5$ to 25 & 9 & $18,25-42$ \\
\hline $181-200$ & 10 & 10 & 10 & from $-22,5$ to 25 & 10 & $8,75-32,5$ & $581-600$ & 10 & 10 & 30 & from $-22,5$ to 25 & 10 & $18,75-42,5$ \\
\hline $201-220$ & 10 & 10 & 20 & from $-22,5$ to 25 & 1 & $9,25-33$ & $601-620$ & 10 & 10 & 40 & from $-22,5$ to 25 & 1 & $19,25-43$ \\
\hline $221-240$ & 10 & 10 & 20 & from $-22,5$ to 25 & 2 & $9,75-33,5$ & $621-640$ & 10 & 10 & 40 & from $-22,5$ to 25 & 2 & $19,75-43,5$ \\
\hline $241-260$ & 10 & 10 & 20 & from $-22,5$ to 25 & 3 & $10,25-34$ & $641-660$ & 10 & 10 & 40 & from $-22,5$ to 25 & 3 & $20,25-44$ \\
\hline $261-280$ & 10 & 10 & 20 & from $-22,5$ to 25 & 4 & $10,75-34,5$ & $661-680$ & 10 & 10 & 40 & from $-22,5$ to 25 & 4 & $20,75-44,5$ \\
\hline $281-300$ & 10 & 10 & 20 & from $-22,5$ to 25 & 5 & $11,25-35$ & $681-700$ & 10 & 10 & 40 & from $-22,5$ to 25 & 5 & $21,25-45$ \\
\hline $301-320$ & 10 & 10 & 20 & from $-22,5$ to 25 & 6 & $11,75-35,5$ & $701-720$ & 10 & 10 & 40 & from $-22,5$ to 25 & 6 & $21,75-45,5$ \\
\hline $321-340$ & 10 & 10 & 20 & from $-22,5$ to 25 & 7 & $12,25-36$ & $721-740$ & 10 & 10 & 40 & from $-22,5$ to 25 & 7 & $22,25-46$ \\
\hline $341-360$ & 10 & 10 & 20 & from $-22,5$ to 25 & 8 & $12,75-36,5$ & $741-760$ & 10 & 10 & 40 & from $-22,5$ to 25 & 8 & $22,75-46,5$ \\
\hline $361-380$ & 10 & 10 & 20 & from $-22,5$ to 25 & 9 & $13,25-37$ & $761-780$ & 10 & 10 & 40 & from $-22,5$ to 25 & 9 & $23,25-47$ \\
\hline $381-400$ & 10 & 10 & 20 & from $-22,5$ to 25 & 10 & $13,75-37,5$ & $781-800$ & 10 & 10 & 40 & from $-22,5$ to 25 & 10 & $23,75-47,5$ \\
\hline
\end{tabular}

Finally, three useful diagrams, of composite rock mass quality and range of Blastability Index (BI), derive from the above estimations (Fig. 2-4). Figure 2 refers to rock mass with close spaced discontinuities. The above rock planes may strike parallel or perpendicular to tunnel axis. The underlying rock, which strike parallel to tunnel axis, may be extremely soft of medium hard or hard and very hard. The blastability index is calculated to be between 14 and 41 for the first case and between 17 and 42 for the second case. Taking into account the surface conditions and the structure of the rock mass, we can estimate the GSI and RMR range. Furthermore, the underlying rock, which strikes perpendicular to tunnel axis, may consist only of gradient discontinuities, when the tunnel drives with dip direction, or consist of gradient and perpendicular discontinuities, when the tunnel drives against dip direction. The blastability index is calculated to be between 19 and 47 for the first case and between 4 and 37 for the second case. Taking into account the surface conditions and the structure of the rock mass, we can estimate the GSI (Hoek., 1994) and RMR range.

Figure 3 refers to rock mass with intermediate spaced discontinuities (Deere and Deere, 1988). The rock mass may consist of horizontal or gradient discontinuities. In case there are only horizontal discontinuities, the rock mass may be extremely soft to soft or medium hard to very hard. The blastability index is calculated between 9 and 34 for the first case and between 11 and 37 for the second case. In case of gradient discontinuities, the rock mass may strike perpendicular to tunnel axis when excavation drives against dip direction, the rock mass may strike perpendicular to tunnel axis when excavation drives with dip direction, and the rock mass may strike parallel to tunnel axis. Where the rock mass strikes perpendicular to tunnel axis, when

XLVII, No $3-1697$ 
excavation drives against dip direction, the rock mass may be extremely soft to medium hard or hard and very hard. The blastability index is calculated between 14 and 46 for the first case and between 17 and 47 for the second case. Where the rock mass strikes perpendicular to tunnel axis, and excavation drives with dip direction, the blastability index is calculated to be between 24 and 52. Where the underling rock strikes parallel to tunnel axis, the rock mass may be medium hard, or extremely soft to soft. The blastability index is calculated to be between 14 and 46 for the first case and between 19 and 44 for the second case. Taking into account the surface conditions and the structure of the rock mass, we can estimate the GSI and RMR range.

Table 3 - BI calculations for intermediating spacing discontinuities.

\begin{tabular}{|c|c|c|c|c|c|c|c|c|c|c|c|c|c|}
\hline $\mathbf{A} / \mathbf{A}$ & RMD & JPS & JPO & $\begin{array}{l}\text { SGI } \\
\end{array}$ & $\mathbf{H}$ & BI & $\mathbf{A} / \mathbf{A}$ & RMD & JPS & JPO & $\begin{array}{l}\text { SGI } \\
\end{array}$ & H & BI \\
\hline $801-820$ & 10 & 20 & 10 & from $-22,5$ to 25 & 1 & $9,25-33$ & $1201-1220$ & 10 & 20 & 30 & from $-22,5$ to 25 & 1 & $19,25-43$ \\
\hline $821-839$ & 10 & 20 & 10 & from $-22,5$ to 25 & 2 & $9,75-33,5$ & 1221-1239 & 10 & 20 & 30 & from $-22,5$ to 25 & 2 & $19,75-43,5$ \\
\hline $841-860$ & 10 & 20 & 10 & from $-22,5$ to 25 & 3 & $10,25-34$ & $1241-1260$ & 10 & 20 & 30 & from $-22,5$ to 25 & 3 & $20,25-44$ \\
\hline $861-880$ & 10 & 20 & 10 & from $-22,5$ to 25 & 4 & $10,75-34,5$ & $1261-1280$ & 10 & 20 & 30 & from $-22,5$ to 25 & 4 & $20,75-44,5$ \\
\hline $881-900$ & 10 & 20 & 10 & from $-22,5$ to 25 & 5 & $\begin{array}{l}11,25-35 \\
\end{array}$ & $1281-1300$ & 10 & 20 & 30 & from $-22,5$ to 25 & 5 & $21,25-45$ \\
\hline 901-920 & 10 & 20 & 10 & from $-22,5$ to 25 & 6 & $11,75-35,5$ & $1301-1320$ & 10 & 20 & 30 & from $-22,5$ to 25 & 6 & $21,75-45,5$ \\
\hline $921-940$ & 10 & 20 & 10 & from $-22,5$ to 25 & 7 & $12,25-36$ & $1321-1340$ & 10 & 20 & 30 & from $-22,5$ to 25 & 7 & $22,25-46$ \\
\hline $941-960$ & 10 & 20 & 10 & from $-22,5$ to 25 & 8 & $12,75-36,5$ & $1341-1360$ & 10 & 20 & 30 & from $-22,5$ to 25 & 8 & $22,75-46,5$ \\
\hline $961-980$ & 10 & 20 & 10 & from $-22,5$ to 25 & 9 & $13,25-37$ & $1361-1380$ & 10 & 20 & 30 & from $-22,5$ to 25 & 9 & $23,25-47$ \\
\hline $981-1000$ & 10 & 20 & 10 & from $-22,5$ to 25 & 10 & $13,75-37,5$ & $1381-1400$ & 10 & 20 & 30 & from $-22,5$ to 25 & 10 & $23,75-47,5$ \\
\hline $1001-1020$ & 10 & 20 & 20 & from $-22,5$ to 25 & 1 & $\begin{array}{l}14,25-38 \\
\end{array}$ & $1401-1420$ & 10 & 20 & 40 & from $-22,5$ to 25 & 1 & $24,25-48$ \\
\hline 1021-1039 & 10 & 20 & 20 & from $-22,5$ to 25 & 2 & $14,75-38,5$ & $1421-1439$ & 10 & 20 & 40 & from $-22,5$ to 25 & 2 & $24,75-48,5$ \\
\hline 1041-1060 & 10 & 20 & 20 & from $-22,5$ to 25 & 3 & \begin{tabular}{|l|}
$15,25-39$ \\
\end{tabular} & $1441-1460$ & 10 & 20 & 40 & from $-22,5$ to 25 & 3 & $25,25-49$ \\
\hline $1061-1080$ & 10 & 20 & 20 & from $-22,5$ to 25 & 4 & $15,75-39,5$ & $1461-1480$ & 10 & 20 & 40 & from $-22,5$ to 25 & 4 & $25,75-49,5$ \\
\hline $1081-1100$ & 10 & 20 & 20 & from $-22,5$ to 25 & 5 & $16,25-40$ & $1481-1500$ & 10 & 20 & 40 & from $-22,5$ to 25 & 5 & $26,25-50$ \\
\hline $1101-1120$ & 10 & 20 & 20 & from $-22,5$ to 25 & 6 & $16,75-40,5$ & $1501-1520$ & 10 & 20 & 40 & from $-22,5$ to 25 & 6 & $26,75-50,5$ \\
\hline $1121-1140$ & 10 & 20 & 20 & from $-22,5$ to 25 & 7 & $17,25-41$ & $1521-1540$ & 10 & 20 & 40 & from $-22,5$ to 25 & 7 & $27,25-51$ \\
\hline $1141-1160$ & 10 & 20 & 20 & from $-22,5$ to 25 & 8 & $17,75-41,5$ & $1541-1560$ & 10 & 20 & 40 & from $-22,5$ to 25 & 8 & $27,75-51,5$ \\
\hline $1161-1180$ & 10 & 20 & 20 & from $-22,5$ to 25 & 9 & $18,25-42$ & 1561-1580 & 10 & 20 & 40 & from $-22,5$ to 25 & 9 & $28,25-52$ \\
\hline $1181-1200$ & 10 & 20 & 20 & from $-22,5$ to 25 & 10 & $18,75-42,5$ & $1581-1600$ & 10 & 20 & 40 & from $-22,5$ to 25 & 10 & $28,75-52,5$ \\
\hline
\end{tabular}

Figure 4 refers to rock mass with widely spaced discontinuities. The rock mass may be extremely soft to soft, medium hard to hard, or hard and very hard. In case the rock mass is extremely soft to soft the discontinuities may be horizontal or gradient with strike perpendicular to tunnel axis, when excavation drives against dip direction, gradient discontinuities with strike perpendicular to tunnel axis, when excavation drives with dip direction, or strike parallel to tunnel axis. The blastability index is calculated to be between 24 and 54 when the discontinuities are horizontal or gradient with strike perpendicular to tunnel axis, when excavation drives against dip direction. The blastability index is calculated to be between 39 and 64 when strike is perpendicular to tunnel axis, when excavation drives with dip direction. The blastability index is calculated to be between 34 and 59 when the strike is parallel to tunnel axis. Concerning medium hard to hard rock mass, the blastability index is calculated to be between 26 and 51 where the discontinuities are horizontal.

Table 4 - BI calculations for widely spacing discontinuities.

\begin{tabular}{|c|c|c|c|c|c|c|c|c|c|c|c|c|c|}
\hline A/A & RMD & JPS & JPO & SGI & $\mathrm{H}$ & BI & A/A & RMD & JPS & JPO & SGI & $\mathrm{H}$ & BI \\
\hline $1601-1620$ & 10 & 50 & 10 & from $-22,5$ to 25 & 1 & $24,25-48$ & $2001-2020$ & 10 & 50 & 30 & from $-22,5$ to 25 & 1 & $34,25-58$ \\
\hline $1621-1640$ & 10 & 50 & 10 & from $-22,5$ to 25 & 2 & $24,75-48,5$ & $2021-2040$ & 10 & 50 & 30 & from $-22,5$ to 25 & 2 & $34,75-58,5$ \\
\hline $1641-1660$ & 10 & 50 & 10 & from $-22,5$ to 25 & 3 & $25,25-49$ & $2041-2060$ & 10 & 50 & 30 & from $-22,5$ to 25 & 3 & $35,25-59$ \\
\hline $1661-1680$ & 10 & 50 & 10 & from $-22,5$ to 25 & 4 & $25,75-49,5$ & $2061-2080$ & 10 & 50 & 30 & from $-22,5$ to 25 & 4 & $35,75-59,5$ \\
\hline $1681-1700$ & 10 & 50 & 10 & from $-22,5$ to 25 & 5 & $26,25-50$ & $2081-2100$ & 10 & 50 & 30 & from $-22,5$ to 25 & 5 & $36,25-60$ \\
\hline $1701-1720$ & 10 & 50 & 10 & from $-22,5$ to 25 & 6 & $26,75-50,5$ & $2101-2120$ & 10 & 50 & 30 & from $-22,5$ to 25 & 6 & $36,75-60,5$ \\
\hline $1721-1740$ & 10 & 50 & 10 & from $-22,5$ to 25 & 7 & $27,25-51$ & $2121-2140$ & 10 & 50 & 30 & from $-22,5$ to 25 & 7 & $37,25-61$ \\
\hline $1741-1760$ & 10 & 50 & 10 & from $-22,5$ to 25 & 8 & $27,75-51,5$ & $2141-2160$ & 10 & 50 & 30 & from $-22,5$ to 25 & 8 & $37,75-61,5$ \\
\hline $1761-1780$ & 10 & 50 & 10 & from $-22,5$ to 25 & 9 & $28,25-52$ & $2161-2180$ & 10 & 50 & 30 & from $-22,5$ to 25 & 9 & $38,25-62$ \\
\hline $1781-1800$ & 10 & 50 & 10 & from $-22,5$ to 25 & 10 & $28,75-52,5$ & $2181-2200$ & 10 & 50 & 30 & from $-22,5$ to 25 & 10 & $38,75-62,5$ \\
\hline $1801-1820$ & 10 & 50 & 20 & from $-22,5$ to 25 & 1 & $29,25-53$ & $2201-2220$ & 10 & 50 & 40 & from $-22,5$ to 25 & 1 & $39,25-63$ \\
\hline $1821-1840$ & 10 & 50 & 20 & from $-22,5$ to 25 & 2 & $29,75-53,5$ & $2221-2240$ & 10 & 50 & 40 & from $-22,5$ to 25 & 2 & $39,75-63,5$ \\
\hline $1841-1860$ & 10 & 50 & 20 & from $-22,5$ to 25 & 3 & $30,25-54$ & $2241-2260$ & 10 & 50 & 40 & from $-22,5$ to 25 & 3 & $40,25-64$ \\
\hline $1861-1880$ & 10 & 50 & 20 & from $-22,5$ to 25 & 4 & $30,75-54,5$ & $2261-2280$ & 10 & 50 & 40 & from $-22,5$ to 25 & 4 & $40,75-64,5$ \\
\hline $1881-1900$ & 10 & 50 & 20 & from $-22,5$ to 25 & 5 & $31,25-55$ & $2281-2300$ & 10 & 50 & 40 & from $-22,5$ to 25 & 5 & $41,25-65$ \\
\hline $1901-1920$ & 10 & 50 & 20 & from $-22,5$ to 25 & 6 & $31,75-55,5$ & $2301-2320$ & 10 & 50 & 40 & from $-22,5$ to 25 & 6 & $41,75-65,5$ \\
\hline $1921-1940$ & 10 & 50 & 20 & from $-22,5$ to 25 & 7 & $32,25-56$ & $2321-2340$ & 10 & 50 & 40 & from $-22,5$ to 25 & 7 & $42,25-66$ \\
\hline $1941-1960$ & 10 & 50 & 20 & from $-22,5$ to 25 & 8 & $32,75-56,5$ & $2341-2360$ & 10 & 50 & 40 & from $-22,5$ to 25 & 8 & $42,75-66,5$ \\
\hline $1961-1980$ & 10 & 50 & 20 & from $-22,5$ to 25 & 9 & $33,25-57$ & $2361-2380$ & 10 & 50 & 40 & from $-22,5$ to 25 & 9 & $43,25-67$ \\
\hline $1981-2000$ & 10 & 50 & 20 & from $-22,5$ to 25 & 10 & $33,75-57,5$ & $2381-2400$ & 10 & 50 & 40 & from $-22,5$ to 25 & 10 & $43,75-67,5$ \\
\hline
\end{tabular}

$\underline{\text { XLVII, No } 3-1698}$ 
The blastability index is calculated to be between 31 and 61 where the strike is perpendicular to tunnel axis, when excavation drives against dip direction. The blastability index is calculated to be between 41 and 66 where the strike is perpendicular to tunnel axis, when excavation drives with dip direction. Concerning hard and very hard rock mass, the blastability index is calculated to be between 27 and 52 where the discontinuities are horizontal. The blastability index is calculated to be between 32 and 57 where strike is perpendicular to tunnel axis, when excavation drives against dip direction. The blastability index is calculated to be between 42 and 67 where strike is perpendicular to tunnel axis, when excavation drives with dip direction. The blastability index is calculated to be between 32 and 62 where strike is parallel to tunnel axis. Taking into account the surface conditions and the structure of the rock mass, we can estimate GSI and RMR range.

\section{Blastability Index (BI) Related to Structural Geology}

Taking into account the calculations of BI for every possible quality of the rock mass, a diagram which connects the structural description, the hardness of rock mass and BI (Fig.5) can be easily developed, where; rock mass quality 1 refers to closely spaced discontinuities (Priest \&Hudson, 1976), horizontal formations, and gradient formations where the excavation drives against dip direction. Rock mass quality 2 refers to intermediate spaced discontinuities and horizontal formations. Rock mass quality 3 refers to closely spaced discontinuities and gradient formations, where excavation drives with dip direction. Rock mass quality 4 refers to intermediate spaced discontinuities and gradient formations. Rock mass quality 5 refers to widely spaced discontinuities, horizontal formations, and soft gradient rock mass, where excavation drives against dip direction. Rock mass quality 6 refers to widely spaced discontinuities and gradient formations (except soft gradient rock mass where excavation drives against dip direction).

Table 5 - RMR estimations for different types of rock mass with specific GSI range.

\begin{tabular}{|c|c|c|c|c|c|c|c|c|c|c|c|c|}
\hline \multirow{2}{*}{ GSI (PART) } & $\begin{array}{l}\text { A/A: } \\
001-80\end{array}$ & $\begin{array}{l}\text { A/A: } \\
81-140\end{array}$ & $\begin{array}{l}\text { A/A: } \\
141-200\end{array}$ & $\begin{array}{l}\text { A/A: } \\
201-280\end{array}$ & $\begin{array}{l}\text { A/A: } \\
281-340\end{array}$ & $\begin{array}{l}\text { A/A: } \\
341-400\end{array}$ & $\begin{array}{l}\text { A/A: } \\
401-480\end{array}$ & $\begin{array}{l}\text { A/A: } \\
481-540\end{array}$ & $\begin{array}{l}\text { A/A: } \\
541-600\end{array}$ & $\begin{array}{l}\text { A/A: } \\
601-680\end{array}$ & $\begin{array}{l}\text { A/A: } \\
681-740\end{array}$ & $\begin{array}{c}\text { A/A: } \\
741-800\end{array}$ \\
\hline & RMR & RMR & RMR & RMR & RMR & RMR & RMR & RMR & RMR & RMR & RMR & RMR \\
\hline $0-12(A)$ & $008-28$ & $009-29$ & $010-30$ & $003-28$ & $004-29$ & $005-30$ & $001-28$ & $002-29$ & $003-30$ & $011-33$ & $0012-34$ & $13-35$ \\
\hline $012-23(\mathrm{~B})$ & $012-32$ & $13-33$ & $14-34$ & $007-32$ & $008-33$ & $009-34$ & $005-32$ & $006-33$ & $007-34$ & $15-37$ & $16-38$ & $17-39$ \\
\hline $22-32(\mathrm{C})$ & $21-40$ & $22-41$ & $23-42$ & $16-40$ & $17-41$ & $18-42$ & $14-40$ & $15-41$ & $16-42$ & $24-45$ & $25-46$ & $26-47$ \\
\hline $007-17(\mathrm{D})$ & $14-33$ & $15-34$ & $16-35$ & $009-33$ & $010-34$ & $011-35$ & $007-33$ & $008-34$ & $009-35$ & $17-38$ & $18-39$ & $19-40$ \\
\hline $018-28(E)$ & $18-37$ & $19-38$ & $20-39$ & $13-37$ & $14-38$ & $15-39$ & $011-37$ & $012-38$ & 13-39 & $21-42$ & $22-43$ & $23-44$ \\
\hline $16-36(\mathrm{~F})$ & $27-45$ & $28-46$ & $29-47$ & $22-45$ & $23-46$ & $24-47$ & $20-45$ & $21-46$ & $22-47$ & $30-50$ & $31-51$ & $32-52$ \\
\hline $35-43(\mathrm{G})$ & $26-44$ & $27-45$ & $28-46$ & $21-44$ & $22-45$ & $23-46$ & $19-44$ & $20-45$ & $21-46$ & $29-49$ & $30-50$ & $31-51$ \\
\hline $42-50(\mathrm{H})$ & $29-47$ & $30-48$ & $31-39$ & $24-47$ & $25-48$ & $26-49$ & $22-47$ & $23-48$ & $24-49$ & $32-52$ & $33-53$ & $34-54$ \\
\hline
\end{tabular}

Table 6- RMR estimations for every GSI classification part.

\begin{tabular}{|c|c|c|c|c|c|c|c|c|c|c|}
\hline \multirow{2}{*}{ GSI (PART) } & $\begin{array}{l}\text { A/A: } \\
801-880\end{array}$ & $\begin{array}{l}\text { A/A: } \\
881-940\end{array}$ & $\begin{array}{l}\text { A/A: } \\
941-1000\end{array}$ & $\begin{array}{c}\text { A/A: } \\
1001-1080\end{array}$ & $\begin{array}{c}\text { A/A: } \\
1081-1140\end{array}$ & $\begin{array}{c}\text { A/A: } 1141- \\
1200\end{array}$ & $\begin{array}{l}\text { A/A: } \\
1201-1280\end{array}$ & $\begin{array}{c}\text { A/A: } \\
1281-1340\end{array}$ & $\begin{array}{l}\text { A/A: } \\
1341-1400\end{array}$ & $\begin{array}{c}\text { A/A: } \\
1401-1480\end{array}$ \\
\hline & RMR & RMR & RMR & RMR & RMR & RMR & RMR & RMR & RMR & RMR \\
\hline $0-12(A)$ & $011-36$ & $012-38$ & $013-37$ & $006-36$ & $007-38$ & $008-39$ & $004-36$ & $005-38$ & $006-39$ & $14-41$ \\
\hline $012-23(\mathrm{~B})$ & $015-39$ & $16-41$ & $17-42$ & $010-40$ & $011-40$ & $012-41$ & $008-39$ & $009-40$ & $010-41$ & $18-44$ \\
\hline $22-32(\mathrm{C})$ & $22-47$ & $23-48$ & $24-49$ & $17-47$ & $18-48$ & $019-49$ & $015-60$ & $16-48$ & $17-49$ & $25-52$ \\
\hline $007-17$ (D) & $012-41$ & $13-42$ & $14-43$ & $007-40$ & $008-41$ & $009-43$ & $006-36$ & $006-41$ & $007-42$ & $15-45$ \\
\hline $018-28(E)$ & $16-44$ & $17-45$ & $18-46$ & $011-44$ & $012-45$ & $13-46$ & $010-40$ & $010-45$ & $011-46$ & $19-49$ \\
\hline $16-36(F)$ & $23-52$ & $24-53$ & $25-54$ & $18-52$ & $019-53$ & $20-54$ & $16-48$ & $017-53$ & $018-54$ & $26-57$ \\
\hline $35-43(\mathrm{G})$ & $29-56$ & $30-57$ & $31-58$ & $24-56$ & $25-57$ & $26-58$ & $22-52$ & $23-57$ & $24-58$ & $32-61$ \\
\hline $42-50(\mathrm{H})$ & $34-58$ & $32-59$ & $33-60$ & $26-58$ & $26-59$ & $28-60$ & $24-54$ & $24-59$ & $25-60$ & $34-63$ \\
\hline
\end{tabular}


Table 7 - RMR estimations for different types of rock mass with specific GSI range.

\begin{tabular}{|c|c|c|c|c|c|c|c|c|c|}
\hline GSI (PART) & $\begin{array}{c}\text { A/A: } \\
1481-1540\end{array}$ & $\begin{array}{c}\text { A/A: } \\
1541-1600\end{array}$ & $\begin{array}{c}\text { A/A: } \\
1601-1680\end{array}$ & $\begin{array}{c}\text { A/A: } \\
1681-1740\end{array}$ & $\begin{array}{c}\text { A/A: } \\
1741-1800\end{array}$ & $\begin{array}{c}\text { A/A: } \\
1801-1880\end{array}$ & $\begin{array}{c}\text { A/A: } \\
1881-1940\end{array}$ & $\begin{array}{c}\text { A/A: } \\
1941-2000\end{array}$ & $\begin{array}{c}\text { A/A: } \\
2001-2080\end{array}$ \\
\hline & RMR & RMR & RMR & RMR & RMR & RMR & RMR & RMR & RMR \\
\hline $0-12(A)$ & $15-42$ & $16-43$ & $13-43$ & $20-58$ & $28-58$ & $008-43$ & $15-58$ & $23-58$ & $006-43$ \\
\hline $012-23(B)$ & $17-45$ & $20-46$ & $15-45$ & $22-60$ & $30-60$ & $011-45$ & $17-60$ & $25-60$ & $008-45$ \\
\hline $22-32(C)$ & $26-53$ & $27-54$ & $\begin{array}{c}29-30 \\
33-42, \\
44-45,49-50\end{array}$ & $\begin{array}{c}36-37, \\
40-57 \\
59-62,64-65\end{array}$ & $\begin{array}{c}42-43 \\
46-55 \\
57-58,62-63\end{array}$ & $\begin{array}{c}24-25 \\
28-42,44-45\end{array}$ & $\begin{array}{c}31-32, \\
35-57 \\
59-62,64-65\end{array}$ & $\begin{array}{c}39-40, \\
43-57 \\
59-60,64-65\end{array}$ & $\begin{array}{c}22-23 \\
26-45,49-50\end{array}$ \\
\hline $007-17(D)$ & $16-46$ & $18-47$ & $13-45$ & $20-58$ & $28-58$ & $008-45$ & $15-58$ & 23-58 & $006-45$ \\
\hline $018-28(E)$ & $20-50$ & $21-51$ & $16-60$ & $23-60$ & $31-60$ & $011-60$ & $18-60$ & $26-60$ & $009-60$ \\
\hline $16-36(F)$ & $27-58$ & $28-59$ & $\begin{array}{c}29-57, \\
59-62,64-65\end{array}$ & $\begin{array}{c}36-37 \\
40-57 \\
59-62,64-65\end{array}$ & $\begin{array}{c}44-45 \\
48-57 \\
59-60,64-65\end{array}$ & $\begin{array}{c}30-69 \\
65-68,70-71\end{array}$ & $\begin{array}{c}31-32, \\
35-57, \\
59-62,64-65\end{array}$ & $\begin{array}{c}34-40, \\
43-57, \\
59-60,64-65\end{array}$ & $22-62,64-65$ \\
\hline $35-43(G)$ & $33-62$ & $34-63$ & $33-71$ & $40-71$ & $48-66,68-71$ & $28-71$ & $35-57$ & $43-66,68-71$ & $26-71$ \\
\hline $42-50(\mathrm{H})$ & $35-64$ & $36-65$ & $\begin{array}{c}37-65 \\
67-70,72-73\end{array}$ & $\begin{array}{c}44-45 \\
48-65 \\
67-70,72-73\end{array}$ & $\begin{array}{c}52-53, \\
56-65, \\
67-68,72-73\end{array}$ & $\begin{array}{c}32-45 \\
67-70,72-73\end{array}$ & $\begin{array}{c}39-40 \\
43-65 \\
67-70,72-73\end{array}$ & $\begin{array}{c}47-48, \\
51-65 \\
67-68,72-73\end{array}$ & $30-70,72-73$ \\
\hline
\end{tabular}

Table 8 - RMR estimations for different types of rock mass with specific GSI range.

\begin{tabular}{|c|c|c|c|c|c|}
\hline \multirow{2}{*}{ GSI (PART) } & A/A: 2081-2140 & A/A:2141-2200 & A/A: 2201-2280 & A/A: 2281-2340 & A/A: 2341-2400 \\
\cline { 2 - 6 } & RMR & RMR & RMR & RMR & RMR \\
\hline $0-12(A)$ & $13-58$ & $45-46,49-68,72-73$ & $16-33$ & $23-61$ & $31-63$ \\
\hline $012-23(B)$ & $15-60$ & $23-60$ & $20-50$ & $25-65$ & $33-65$ \\
\hline $22-32(\mathrm{C})$ & $29-30,33-62,64-65$ & $37-38,41-60,64-65$ & $32-50,52-55$ & $39-70$ & $47-65,67-70$ \\
\hline $007-17(\mathrm{D})$ & $13-58$ & $21-58$ & $16-50$ & $23-63$ & $31-63$ \\
\hline $018-28(\mathrm{E})$ & $16-60$ & $24-60$ & $19-65$ & $26-65$ & $34-65$ \\
\hline $16-36(\mathrm{~F})$ & $29-33,34-62,64-65$ & $37-38,41-60,64-65$ & $32-70$ & $39-70$ & $47-65,67-70$ \\
\hline $35-43(\mathrm{G})$ & $33-71$ & $41-66,68-71$ & $36-76$ & $43-76$ & $51-76$ \\
\hline $42-50(\mathrm{H})$ & $37-38,41-70,72-73$ & $42-46,49-68,72-73$ & $40-78$ & $47-78$ & $55,-73,75-78$ \\
\hline
\end{tabular}

Looking at the above diagram, we can easily conclude that

- The wider the spacing of discontinuities is, the bigger the BI is.

- The BI is lower in horizontal formations than in gradient formations.

- The BI is higher where the excavation drives with dip direction than where it drives against dip direction.

Table 9 - GSI estimations for different types of rock mass with specific RMR range.

\begin{tabular}{|c|c|c|c|c|c|c|c|c|c|c|c|c|}
\hline \multirow{3}{*}{ RMR } & $\begin{array}{c}\text { A/A: } \\
001-80\end{array}$ & $\begin{array}{c}\text { A/A: } \\
81-140\end{array}$ & $\begin{array}{c}\text { A/A: } \\
141-200\end{array}$ & $\begin{array}{c}\text { A/A: } \\
201-280\end{array}$ & $\begin{array}{c}\text { A/A: } \\
281-340\end{array}$ & $\begin{array}{l}\text { A/A: } \\
341-400\end{array}$ & $\begin{array}{c}\text { A/A: } \\
401-480\end{array}$ & $\begin{array}{c}\text { A/A: } \\
481-540\end{array}$ & $\begin{array}{c}\text { A/A: } \\
541-600\end{array}$ & $\begin{array}{l}\text { A/A: } \\
601-680\end{array}$ & $\begin{array}{c}\text { A/A: } \\
681-740\end{array}$ & $\begin{array}{c}\text { A/A: } \\
741-800\end{array}$ \\
\hline & Bl: 4-29 & Bl: 6-31 & Bl: 7-32 & BI: 9-34 & $\begin{array}{c}\text { Bl: } \\
11-36\end{array}$ & $\begin{array}{c}\mathrm{Bl}: \\
12-37\end{array}$ & $\begin{array}{c}\mathrm{Bl}: \\
14-39\end{array}$ & $\begin{array}{c}\mathrm{Bl}: \\
16-41\end{array}$ & $\begin{array}{c}\mathrm{Bl}: \\
17-42\end{array}$ & $\begin{array}{c}\mathrm{Bl}: \\
19-44\end{array}$ & $\begin{array}{c}\mathrm{Bl}: \\
21-46\end{array}$ & $\begin{array}{c}\mathrm{Bl}: \\
22-47\end{array}$ \\
\hline & $\begin{array}{c}\text { GSI } \\
\text { (PART) }\end{array}$ & $\begin{array}{c}\text { GSI } \\
\text { (PART) }\end{array}$ & $\begin{array}{c}\text { GSI } \\
\text { (PART) }\end{array}$ & $\begin{array}{c}\text { GSI } \\
\text { (PART) }\end{array}$ & $\begin{array}{c}\text { GSI } \\
\text { (PART) }\end{array}$ & $\begin{array}{c}\text { GSI } \\
\text { (PART) }\end{array}$ & $\begin{array}{c}\text { GSI } \\
\text { (PART) }\end{array}$ & $\begin{array}{c}\text { GSI } \\
\text { (PART) }\end{array}$ & $\begin{array}{c}\text { GSI } \\
\text { (PART) }\end{array}$ & $\begin{array}{c}\text { GSI } \\
\text { (PART) }\end{array}$ & $\begin{array}{c}\text { GSI } \\
\text { (PART) }\end{array}$ & $\begin{array}{c}\text { GSI } \\
\text { (PART) }\end{array}$ \\
\hline $0-20$ & ABDE & ABDE & ABDE & ABCDE & ABCDE & ABCDE & $\begin{array}{c}\text { ABCDE } \\
\text { FG }\end{array}$ & $\begin{array}{c}\text { ABCDE } \\
\text { FG }\end{array}$ & ABCDE & ABD & ABD & ABD \\
\hline $21-40$ & $\begin{array}{c}\text { ABCDEF } \\
\text { GH }\end{array}$ & $\begin{array}{c}\text { ABCDEF } \\
\text { GH }\end{array}$ & $\begin{array}{c}\text { ABCDEF } \\
\text { GH }\end{array}$ & $\begin{array}{c}\text { ABCDEF } \\
\text { GH }\end{array}$ & $\begin{array}{c}\text { ABCDE } \\
\text { FGH }\end{array}$ & $\begin{array}{c}\text { ABCDE } \\
\text { FGH }\end{array}$ & $\begin{array}{c}\text { ABCDE } \\
\text { FGH }\end{array}$ & $\begin{array}{c}\text { ABCDE } \\
\text { FGH }\end{array}$ & $\begin{array}{c}\text { ABCDE } \\
\text { FGH }\end{array}$ & $\begin{array}{c}\text { ABCDE } \\
\text { FGH }\end{array}$ & $\begin{array}{c}\text { ABCDE } \\
\text { FGH }\end{array}$ & $\begin{array}{c}\text { ABCDE } \\
\text { FGH }\end{array}$ \\
\hline $41-60$ & FGH & CFGH & CFGH & FGH & $\mathrm{FGH}$ & CFGH & FGH & $\mathrm{FGH}$ & CFGH & CEFGH & CEFGH & CEFGH \\
\hline $61-80$ & & & & & & & & & & & & \\
\hline $81-100$ & & & & & & & & & & & & \\
\hline
\end{tabular}




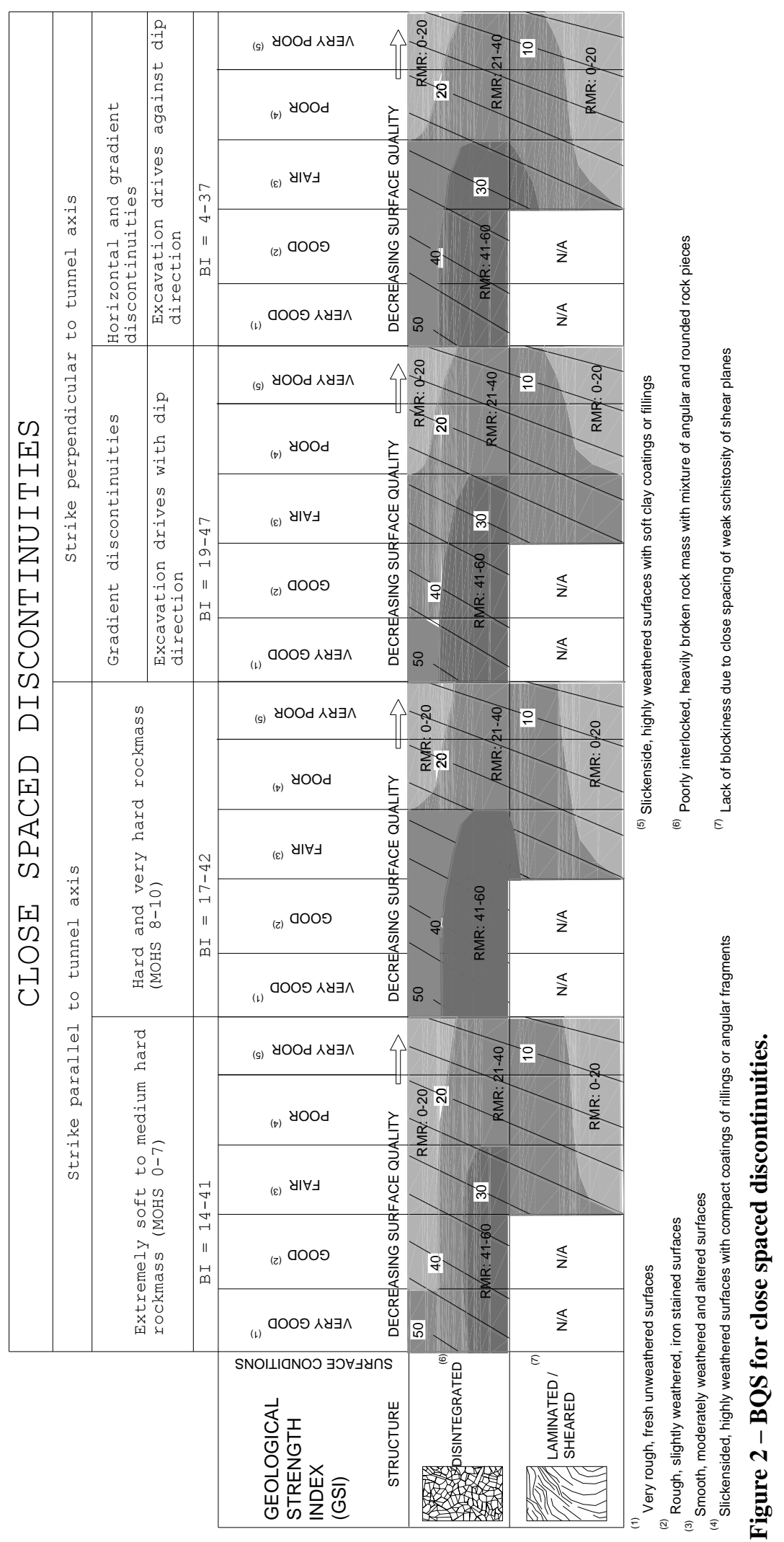

XLVII, No 3 - 1701 


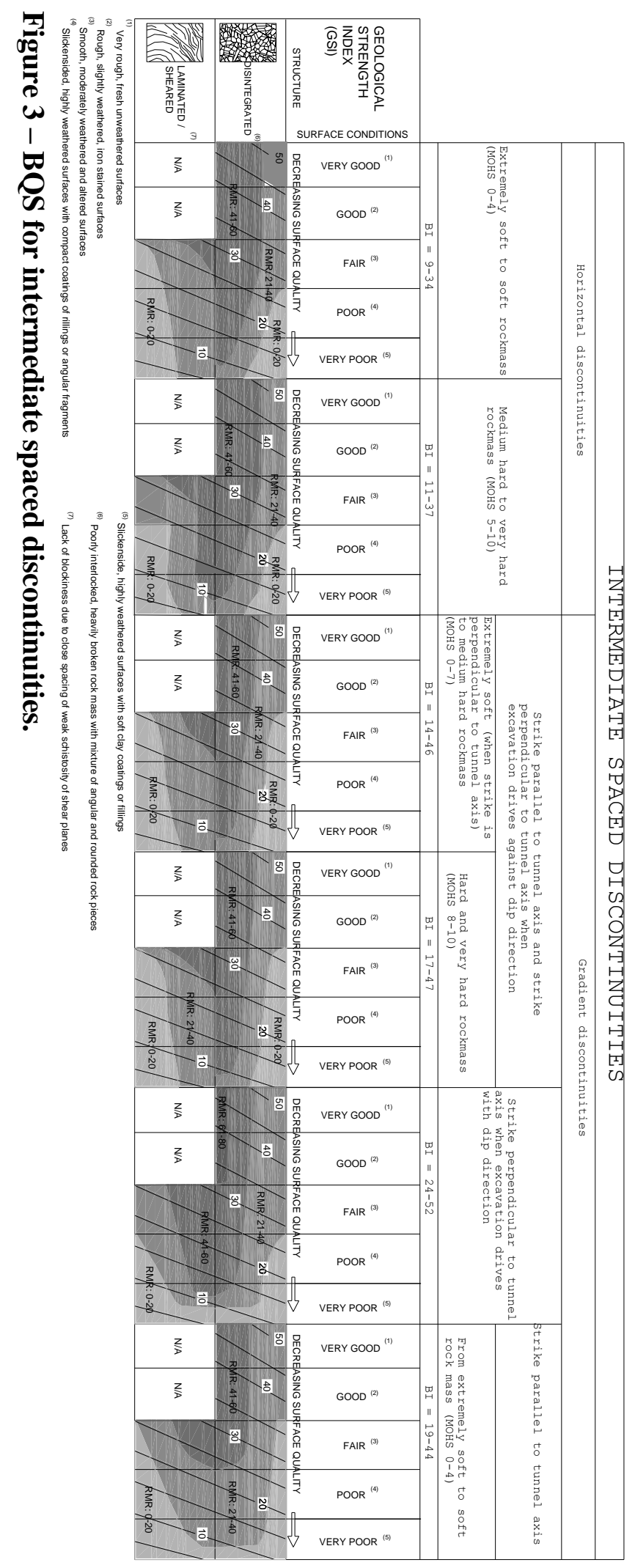

XLVII, No 3 - 1702 


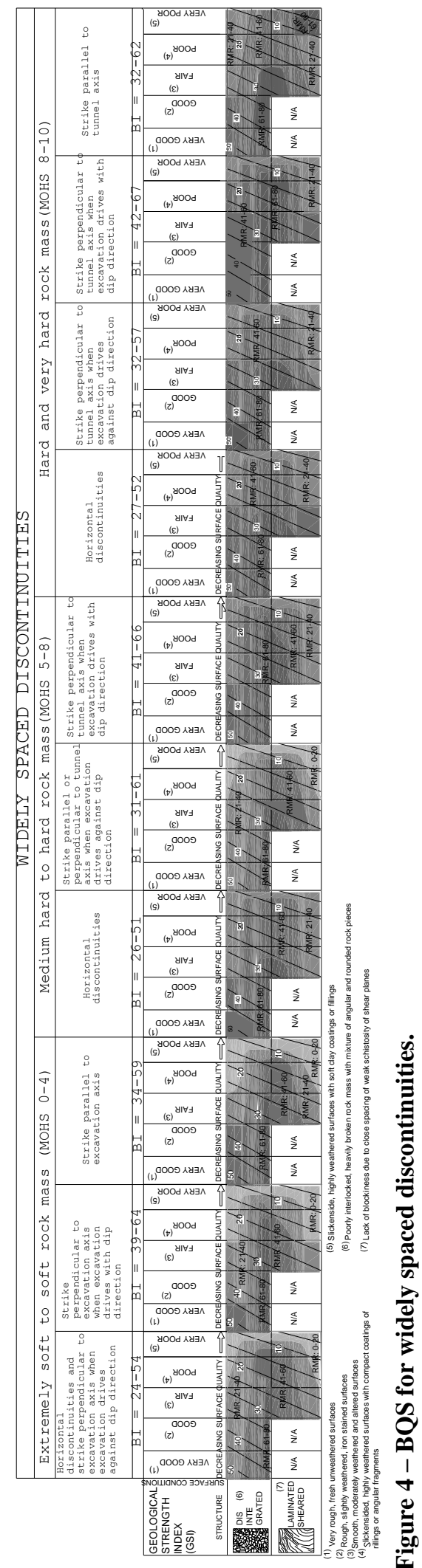

$\underline{\text { XLVII, No } 3-1703}$ 
Table 10 - GSI estimations for different types of rock mass with specific RMR range.

\begin{tabular}{|c|c|c|c|c|c|c|c|c|}
\hline \multirow{3}{*}{ RMR } & A/A: $801-880$ & A/A: $881-940$ & $\begin{array}{c}\text { A/A: } \\
941-1000\end{array}$ & $\begin{array}{c}\text { A/A: } \\
1001-1080\end{array}$ & $\begin{array}{c}\text { A/A: } \\
1081-1140\end{array}$ & $\begin{array}{c}\text { A/A: } \\
1141-1200\end{array}$ & $\begin{array}{c}\text { A/A: } \\
1201-1280\end{array}$ & $\begin{array}{c}\text { A/A: } \\
1281-1340\end{array}$ \\
\hline & Bl:9-34 & BI:11-36 & Bl:12-37 & BI:14-39 & BI:16-41 & Bl:17-42 & Bl:19-44 & BI:21-46 \\
\hline & GSI (PART) & GSI (PART) & GSI (PART) & GSI (PART) & GSI (PART) & GSI (PART) & GSI (PART) & GSI (PART) \\
\hline $0-20$ & $\mathrm{ABCDE}$ & ABDE & $\mathrm{ABDE}$ & ABCDEF & ABCDEF & $\mathrm{ABCDE}(\mathrm{F})$ & ABCDEF & $A B C D E F$ \\
\hline $21-40$ & ABCDEFGH & ABCDEFGH & ABCDEFGH & ABCDEFGH & ABCDEFGH & ABCDEFGH & ABCDEFGH & ABCDEFGH \\
\hline $41-60$ & $\mathrm{C}(\mathrm{D}) \mathrm{EFGH}$ & (B)CDEFGH & BCDEFGH & CEFGH & $\mathrm{C}(\mathrm{D}) \mathrm{EFGH}$ & (B)CDEFGH & $\mathrm{CGH}$ & $\mathrm{C}(\mathrm{D})$ EFGH \\
\hline $61-80$ & & & & & & & & \\
\hline $81-100$ & & & & & & & & \\
\hline
\end{tabular}

Table 11 - GSI estimations for different types of rock mass with specific RMR range.

\begin{tabular}{|c|c|c|c|c|c|c|c|c|}
\hline & $\begin{array}{c}\text { A/A: } \\
1341-1400\end{array}$ & $\begin{array}{c}\text { A/A: } \\
1401-1480\end{array}$ & $\begin{array}{c}\text { A/A: } \\
1481-1540\end{array}$ & $\begin{array}{c}\text { A/A: } \\
1541-1600\end{array}$ & $\begin{array}{c}\text { A/A: } \\
1601-1680\end{array}$ & $\begin{array}{c}\text { A/A: } \\
1681-1740\end{array}$ & $\begin{array}{c}\text { A/A: } \\
1741-1800\end{array}$ & $\begin{array}{c}\text { A/A: } \\
1801-1880\end{array}$ \\
\hline RMR & $B \mathrm{Bl}: 22-47$ & Bl:24-49 & Bl:26-51 & BI:27-52 & Bl:24-49 & $\mathrm{Bl}: 26-51$ & $\mathrm{Bl}: 27-52$ & Bl:29-54 \\
\hline & GSI (PART) & GSI (PART) & GSI (PART) & GSI (PART) & GSI (PART) & GSI (PART) & GSI (PART) & GSI (PART) \\
\hline $0-20$ & ABCDEF & ABDE & $\mathrm{ABD}(\mathrm{E})$ & $A(B) D$ & ABDE & & & ABDE \\
\hline $21-40$ & ABCDEFGH & ABCDEFGH & ABCDEFGH & ABCDEFGH & ABCDEFGH & ABCDEF & $\mathrm{ABDE}$ & ABCDEFGH \\
\hline $41-60$ & CDEFGH & (A)BCDEFGH & ABCDEFGH & ABCDEFGH & BCDEFGH & ABCDEFGH & ABCDEFGH & ABCDEFGH \\
\hline $61-80$ & & (G) $\mathrm{H}$ & $\mathrm{GH}$ & $\mathrm{GH}$ & FGH & CFGH & CFGH & FGH \\
\hline $81-100$ & & & & & & & & \\
\hline
\end{tabular}

Table 12 - GSI estimations for different types of rock mass with specific RMR range.

\begin{tabular}{|c|c|c|c|c|c|c|c|c|}
\hline & $\begin{array}{c}\text { A/A: } \\
1881-1940\end{array}$ & $\begin{array}{c}\text { A/A: } \\
1941-2000\end{array}$ & $\begin{array}{c}\text { A/A: } \\
2001-2080\end{array}$ & $\begin{array}{c}\text { A/A: } \\
2081-2140\end{array}$ & $\begin{array}{c}\text { A/A: } \\
2141-2200\end{array}$ & $\begin{array}{c}\text { A/A: } \\
2201-2280\end{array}$ & $\begin{array}{c}\text { A/A: } \\
2281-2340\end{array}$ & $\begin{array}{c}\text { A/A: } \\
2341-2400\end{array}$ \\
\hline RMR & Bl:31-56 & $\mathrm{Bl}: 32-57$ & Bl:34-59 & Bl:36-61 & Bl:37-62 & $\mathrm{Bl}: 39-64$ & $\mathrm{BI}: 41-66$ & Bl: $42-67$ \\
\hline & GSI (PART) & GSI (PART) & GSI (PART) & GSI (PART) & GSI (PART) & GSI (PART) & GSI (PART) & GSI (PART) \\
\hline $0-20$ & ABDE & & ABDE & ABDE & & $\mathrm{A}(\mathrm{B}) \mathrm{DE}$ & & \\
\hline $21-40$ & ABCDEFGH & $\mathrm{AB}(\mathrm{C}) \mathrm{DEF}$ & ABCDEFG & ABCDEFGH & BCDEF & ABCDEFG & ABCDEF & $\mathrm{ABD}$ \\
\hline $41-60$ & ABCDEFGH & ABCDEFG & ABCDEFGH & ABCDEFGH & ABCDEFGH & BCDEFGH & ABCDEFGH & ABCDEFGH \\
\hline $61-80$ & CFGH & (CF)GH & FGH & CFGH & ACFGH & EFGH & BCDEFGH & ABCDEFGH \\
\hline $81-100$ & & & & & & & & \\
\hline
\end{tabular}

\section{Blastability Quality System (BQS)}

The Blastability Quality System (BQS) is a very useful approach as it includes the most useful characteristics of rock mass, which are easily estimated and used in situ. In addition to its easy and wide use, it is a quick calculator for BI and rock mass quality, which make our choice of excavation, blast (Hino, 1959) and support measures quicker.

The BQ system (Fig. 2-4) connects the rock mass classification systems RMR and GSI, structural data, hardness of rock mass, and BI.

Initially, the discontinuities spacing is characterized. Secondly, the orientation of discontinuities in addition to the hardness of the rock mass is described. Having completed the above classification, the BI range can easily be determined. By visually inspecting the rock mass, we can easily distinguish discontinuity spacing and orientation. Also, we can estimate rock mass hardness

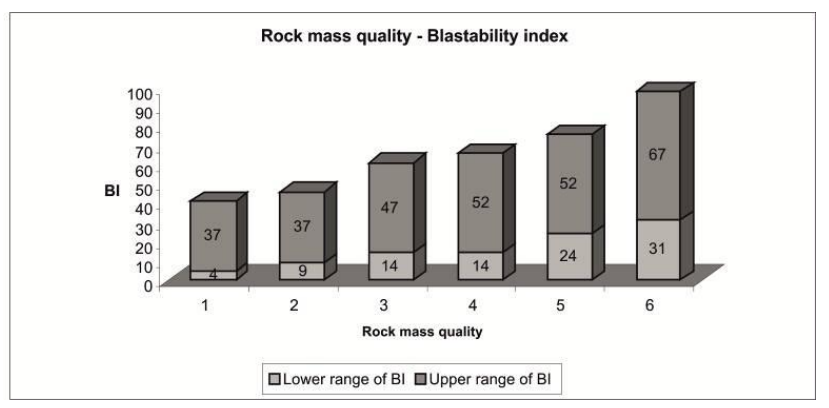

Figure 5 - Rock mass quality versus BI. using a Schmidt Hammer.

Finally we can combine structure and surface conditions in order to estimate Geological Strength Index (GSI) (Hoek \& Brown, 1980) and Rock Mass Rating (RMR). 


\section{Conclusions}

Taking into account the calculations of BI for every possible poor rock mass quality, the wider the spacing of discontinuities is, the bigger the BI is. The BI is, also, lower in horizontal formations than in gradient formations. Finally, the BI is higher, in cases where the excavation drives with dip direction than where it drives against it.

Evaluating the rock mass quality estimated by the RMR and GSI classification systems together with the calculated blastability index, a useful system, called Blastability Quality System (BQS), is created.

This "blastability quality system" can be a useful "in-situ tool", for estimating poor and friable rock masses, shared with lack of blockiness due to close spacing of weak schistosity or sheer planes and disintegrated, with poorly interlocked, heavily broken, with mixture of angular and rounded rock pieces. It connects rock mass quality, discontinuity orientation, rock mass hardness and BI. It can be easily applied during the excavations, in order to estimate rock mass quality and the range of BI very quickly. This is a viable tool for estimating the quantity of explosions and support measures to be decided using the already known methodology.

\section{References}

Barton N.R., Lien R. and Lunde J. 1980. Application of the Q-system in design decisions, in Subsurface space, (eds. M. Bergman) 2, 553-561. New York: Pergamon.

Bieniawski Z.T. 1989. Engineering rock mass classifications. New York: Wiley.

Deere D.U. and Deere D.W. 1988. The rock quality designation (RQD) index in practice, in Rock classification systems for engineering purposes, (eds. L. Dirkaldie), ASTM Special Publication 984, 91-101. Philadelphia: Am. Soc. Test. Mat.

Deere D.U. 1989. Rock puality designation (RQD) after 20 years. U.S. Army Corps Engrs Contract Report GL-89-1, Vicksburg, MS: Waterways Experimental Station.

Hino K. 1959. Theory and Practice of Blasting, Noppon Kayaku Co, Ltd, Japan

Hoek E. 1983. Strength of jointed rock masss, $23^{\text {rd }}$ Rankine Lecture. Geotechnique 33(3), 187-223

Hoek E. 1994. Strength of rock and rock masses, ISRM News Journal, 2(2). 4-16.

Hoek E. and Brown E.T. 1980. Empircal strength criterion of rock masses, J. Geotech Engng. Div., ASCE, 106 (gt9), 1013-1035.

Hoek E. and Brown, ET. 1997. Practical estimates of rock mass strength Int. J. Rock Mech Min Sci 1997; 34(8):1165-86.

Hoek E., Marinos P. and Benissi M. 1998. Applicability of the Geological Strength Index (GSI) classification for very weak and sheared rock masses. The case of the Athens Schist Formation, Bull. Engg. Geol. Env. 57(2), 151-160.

Jimeno C.L., Jinemo E.L. and Carcedo F.J.A. 1995. Drilling \& Blasting of Rocks, A.A.Bulkema, Rotterdum, Brookfield Publication, pp160-180.

Kaushik D. and Phalguni S. 2003. Concept of Blastability - An Update, The Indian Mining \& Engineering Journal, Vol-42, No.-8\&9, pp24-31.

Lilly P. 1986. An Empirical Method of Assessing Rockmass blastability, Large Open Pit Mine Conference, Newman, Australia, October, pp89-92.

Marinos P. and Hoek E. 2000. GSI - A geologically friendly tool for rock mass strength estimation, Proc. GeoEng2000 Conference, Melbourne. 1422-1442.

Murthy, V., Day, K. and Raitani R., 2003. Prediction of overbreak in underground tunnel blasting, A case study, Journal of Canadian Tunneling Canadien, P109-115.

Priest S.D. and Hudson J.A. 1976. Discontinuity spacings in rock. Int. Jour. Rock. Mech. Min. Sci. \& Gomech, v.13, p.135-148.

Scott A. 1996. Blastability and Blast Design, Rock Gragmentation by Bloastin, (ed) Mohanty, Balkema, Rotterdam, pp27-36. 